\title{
Threshold behavior of karst aquifers: the example of the Lurbach karst system (Austria)
}

\author{
S. Birk $\cdot$ T. Wagner $\cdot$ C. Mayaud
}

Received: 13 December 2013/ Accepted: 2 February 2014/Published online: 15 March 2014

(C) The Author(s) 2014. This article is published with open access at Springerlink.com

\begin{abstract}
Threshold behavior in hydrological systems generally involves a qualitative change of a single process, the system response or the functioning of the system. Different types of thresholds and their underlying controls are examined using the example of the Lurbach karst system (Austria). This karst system receives allogenic recharge from the sinking stream Lurbach, which under low-flow conditions only resurges at the Hammerbach spring. Yet, under medium- to high-flow conditions an overflow toward another spring, the Schmelzbach outlet occurs. Thresholds in physicochemical spring responses and their underlying controls are identified from the analysis of heat and solute transport processes in karst conduits. Applying this concept to the Hammerbach spring suggests that the threshold controlling the response of the spring water temperature was changed in the time period from 2006 to 2009 relative to the years before. At the same time, changes are observed in the behavior of the spring hydrograph and the discharge threshold at which the overflow to the Schmelzbach system is activated. All of these observations can be consistently explained by a decreased diameter of the conduit pathways within the indicated time period, presumably caused by the redistribution of sediments due to a flood event in 2005. Thus, thresholds in the physicochemical spring response were successfully employed to support the identification of a change in the functioning of the Lurbach karst system, which occurred possibly because a threshold related to the sediment transport within the karst conduits was crossed.
\end{abstract}

S. Birk $(\bowtie) \cdot$ T. Wagner $\cdot$ C. Mayaud

Institut für Erdwissenschaften, Karl-Franzens-Universität Graz, 8010 Graz, Austria

e-mail: steffen.birk@uni-graz.at
Keywords Karst catchments · Heat transport . Water temperature $\cdot$ Tracers $\cdot$ Thresholds

\section{Introduction}

Threshold behavior in hydrological systems generally involves a qualitative change of a single process, the system response or the functioning of the system (Zehe and Sivapalan 2009). The transition from laminar to turbulent flow (or vice versa) represents a well-known example of threshold behavior at the process level, which occurs when the Reynolds number (representing the ratio of inertial forces to viscous forces) crosses an empirical threshold value. This transition is likely to occur within solution conduits of karst aquifers when flow velocities change after recharge events. Theoretical considerations suggest that this process threshold may strongly influence the hydrological response of springs draining these aquifers (Reimann et al. 2011). The aquifer response, however, is governed by multiple interacting processes and flow components. Assessing if and under which conditions thresholds are actually crossed in the response of a spring or the functioning of the aquifer thus is not straightforward.

If the aquifer (or any other hydrological system) is close to a threshold, a small parameter change suffices to cause a qualitative change in the aquifer response. Any uncertainty in state variables or aquifer parameters thus causes high prediction uncertainty (Fig. 1a). This is particularly challenging if coupled environmental systems are considered using model chains. An example is provided by climate change impact assessments where projections from global circulation models are downscaled and passed to hydrological models, which then provide the input for ecological or socioeconomic models. Within each of these steps, sub- 


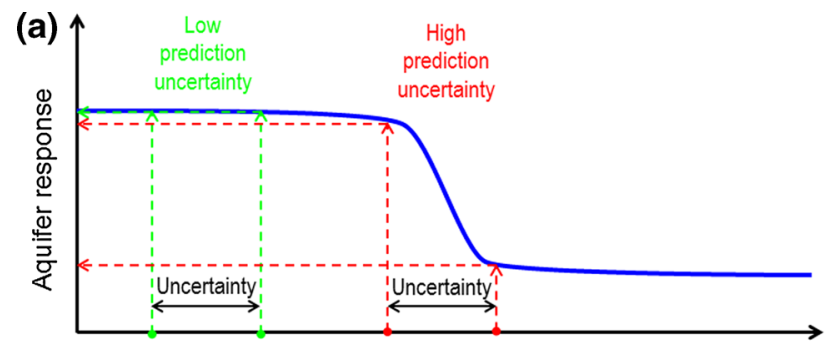

State variables or aquifer parameters

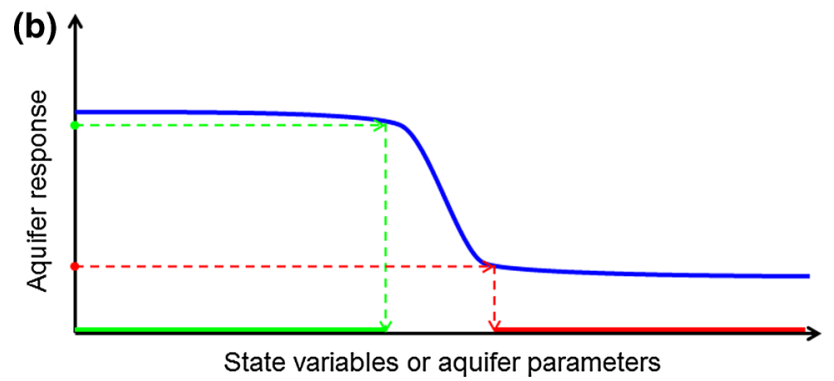

Fig. 1 Relationship between state variables or aquifer parameters and aquifer response close to a threshold: Consequences for a the prediction of aquifer responses and $\mathbf{b}$ the characterization of state variables or aquifer parameters (modified after Zehe and Sivapalan 2009)

systems are considered where thresholds might be crossed. Thus, it is hardly feasible to account for the full range of uncertainty in the projections, and consequently it is often attempted to represent some uncertainty using a scenariobased approach. As a consequence, it has been suggested that in a decision-making context, analysis of a system's vulnerability may provide more insights than such projections of future climate impacts (Brown and Wilby 2012). If the focus is shifted from prediction to characterization, thresholds may turn from a challenge to an opportunity as illustrated by Fig. 1b. The aquifer response is highly sensitive to variations in state variables or aquifer parameters if the system is close to a threshold. This suggests that information about the state variables or aquifer parameters can be inferred from the observed response if the mechanism governing the threshold behavior is well understood.

The purpose of this paper is to explore thresholds in karst aquifers and their underlying control using the example of the Lurbach system (Austria), which is well understood from earlier investigations and exhibits different types of thresholds. To this end, a method that makes use of thresholds in the transport processes is introduced and applied for analyzing the physicochemical spring responses (section transport thresholds). The results from this analysis are then compared to earlier findings from tracer tests and spring hydrographs (section discussion) to derive conclusions with respect to thresholds in the response or functioning of this karst system.

\section{Field site}

The Lurbach system, situated approximately $20 \mathrm{~km}$ north of Graz (Austria), comprises an area of $8 \mathrm{~km}^{2}$ composed of highly karstfied Paleozoic carbonate rocks that receive concentrated allogenic recharge from the sinking stream Lurbach, which drains an area of $15 \mathrm{~km}^{2}$ mainly composed of lowly permeable Paleozoic schists and Quaternary sediments (Fig. 2). The carbonate rocks are drained by two springs, the Schmelzbach outlet and the Hammerbach spring. The conduit system draining towards the Hammerbach spring is not accessible and therefore its geometry is unknown. However, other parts of the karst system are explored. In addition to numerous dry caves that are usually blocked by sediment or collapse material after a certain stretch which impedes further exploration, there is a water-active show cave that is accessible at the Schmelzbach outlet and via another entrance close to the major sinkhole of the Lurbach on the other side of the karst massive.

Behrens et al. (1992) provide an overview of the hydrogeology of this karst system. In particular, they present results from numerous tracer tests conducted under different hydrological conditions, showing that the Hammerbach spring represents the only resurgence of the sinking stream under low water conditions. At medium or high water conditions, however, tracer injected at the stream sink was also recovered at the Schmelzbach outlet. This suggests that an overflow from the Hammerbach system to the Schmelzbach system is activated when a certain hydrological threshold is crossed. Similar influences of hydrological conditions on flow connections and thus on the relative contributions of allogenic and autogenic flow components have also been reported from other karst systems (e.g., Ravbar et al. 2012; Bonacci et al. 2013; Terzić et al. 2014).

Multiple, distinct, cave levels can be distinguished in the Lurbach karst system (Wagner et al. 2010, 2011a). Thus, the overflow is probably activated when conduits at a distinct elevation are flooded, which suggests that a threshold value of hydraulic heads can be defined. However, observation wells are not existent in this area and thus hydraulic head data are not available. Therefore, the aforementioned "low water conditions" refer to the discharge of the Hammerbach spring, for which a long-term record is available.

Behrens et al. (1992) found that the overflow to the Schmelzbach system was active when the Hammerbach spring discharge exceeded approximately 200 1/s. In 2008, however, a low percentage of a tracer injected in the Lurbach stream was recovered at the Schmelzbach spring, when the Hammerbach discharge was only approximately 140 1/s (Oswald 2009; Wagner et al. 2011b). Thus, 


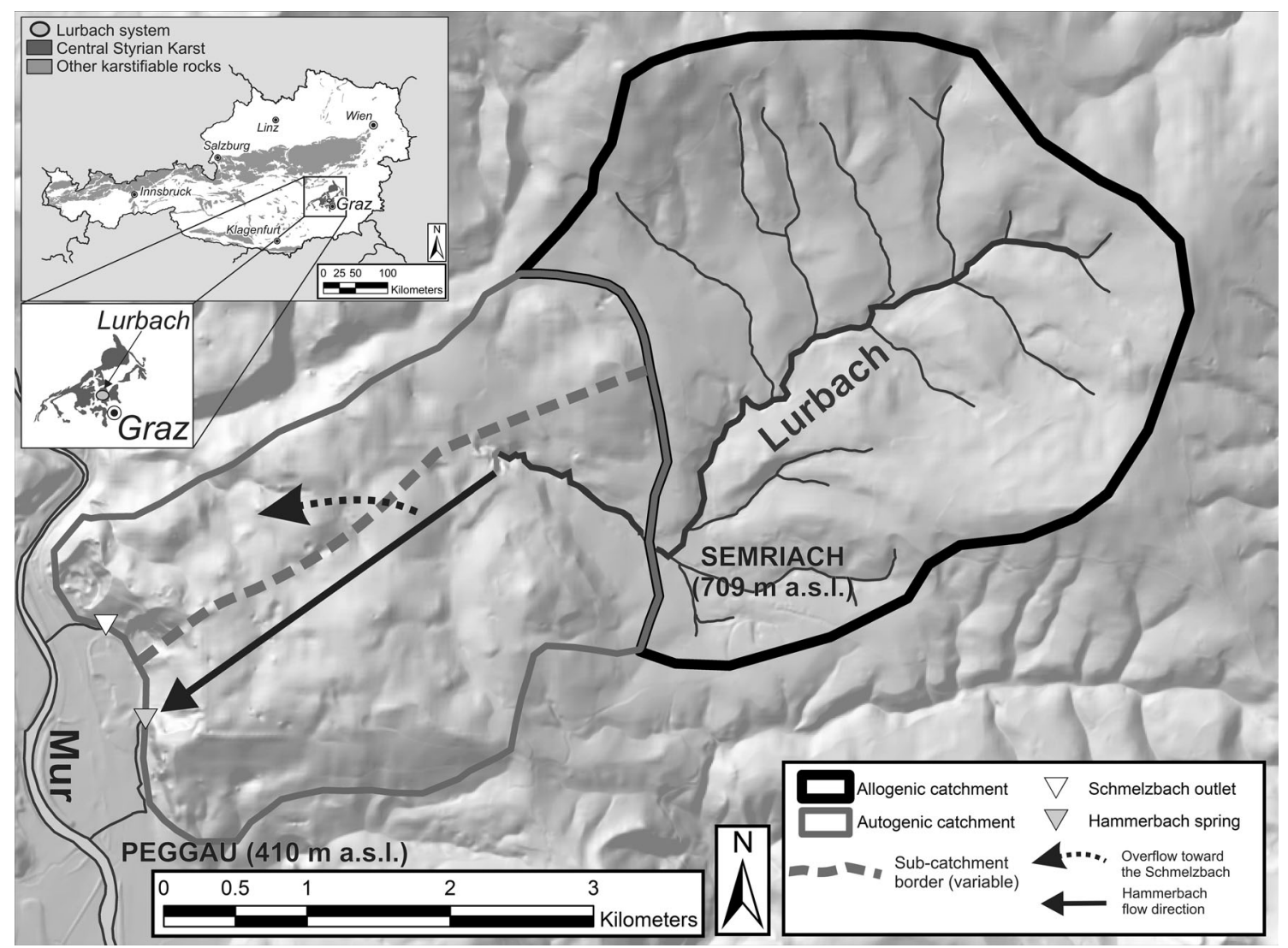

Fig. 2 Location and simplified map of the Lurbach karst system (Austria) showing the catchment boundaries and main hydrological features

although this threshold appears to be conceptually well understood, a consistent threshold value of the Hammerbach discharge at which the overflow is activated cannot be defined based on the available tracer test data. In the following section, time series of physicochemical parameters of the Hammerbach spring are analyzed to obtain more insight into the transport behavior and associated thresholds of the Lurbach system. It is noteworthy that a continuous long-term data record is available only for the Hammerbach spring but not for the Schmelzbach outlet and the Lurbach stream.

\section{Transport thresholds}

Time series of temperature and electrical conductivity of the spring water are among the most frequently available data from karst springs. While the water temperature is controlled by heat transport processes, the electrical conductivity reflects the effect of reactive solute transport processes in the aquifer. In general, calcium and bicarbonate ions from the dissolution of calcite or aragonite can be assumed to be the major control on the electrical conductivity of waters from carbonate aquifers. However, in karst systems with concentrated allogenic recharge, such as the Lurbach stream, the allogenic flow component may provide additional solutes contributing to the electrical conductivity.

Since heat and solute transport are governed by different processes, it has been suggested that temperature and concentration (or electrical conductivity) of the spring water provide complementary information about the aquifer characteristics (Birk et al. 2006). A corresponding theoretical framework was developed by Covington et al. (2012) by deriving "process length scales" of heat and solute transport. These length scales represent approximations of the maximum distance for the propagation of thermal and concentration pulses along karst conduits. Temperature or concentration pulses introduced by the recharging water are strongly damped (and thus not detectable) if the travel distance is much larger than the respective length scale. For many purposes it may be useful to refer to time scales instead of length scales, because even if the travel distance is unknown, the travel times can either be inferred from tracer tests or from the time lag between the increase of spring discharge and subsequent physicochemical responses at the spring.

Heat transport in water-filled karst conduits is governed by convection along the conduit and conduction in the 
rock. A thorough analysis of heat transport processes in karst conduits under turbulent flow conditions reveals that the heat exchange rates are usually limited by conduction and thus the temperature at the conduit wall is nearly at water temperature (Covington et al. 2011). The length scale $\lambda_{T}$ derived under these assumptions (Eq. 19 in Covington et al. 2012) can be easily transformed to a time scale $\tau_{T}$ by setting the velocity $V=\lambda_{T} / \tau_{T}$ yielding

$\tau_{\mathrm{T}}=\frac{1}{4} \sqrt{\frac{\pi^{2} \Psi^{4} D_{\mathrm{H}}^{4}}{64 \alpha_{\mathrm{r}}^{2}}+\frac{\pi \Psi^{2} D_{H}^{2}}{\alpha_{\mathrm{r}}} t_{0}}-\frac{\pi \Psi^{2} D_{\mathrm{H}}^{2}}{32 \alpha_{\mathrm{r}}}$

where $t_{0}$ is the duration of the recharge pulse, $\alpha_{\mathrm{r}}$ is the thermal diffusivity of rock, $\Psi$ is a ratio of the volumetric heat capacities of water and rock, and $D_{\mathrm{H}}$ is the hydraulic diameter of the conduit.

Covington et al. (2012) also provide a thorough discussion of the processes limiting the dissolution of limestone and thus the concentration of dissolved calcium and bicarbonate, which can often be assumed to be the major control on the electrical conductivity of karst spring waters. Under turbulent flow conditions, the surface reaction is limiting the overall dissolution rate. Assuming the kinetics of the surface reaction can be represented by a linear rate law, which is reasonable if the water is not close to chemical equilibrium, a dissolution length scale is derived (Eq. 15 in Covington et al. 2012). Transforming this length scale to a time scale yields

$\tau_{\mathrm{D}}=\frac{D_{\mathrm{H}}}{4 \alpha}$

where $\alpha$ is the constant from the linear dissolution rate law. Under laminar flow conditions, the linear dissolution rate law and thus the time scale given by Eq. (2) are still valid but the coefficient $\alpha$ will be lower if diffusion becomes rate-limiting. If the diffusion coefficient is known, the value of $\alpha$ under laminar flow conditions can be calculated using a relationship proposed by Dreybrodt (1988).

The time scales defined by the two above equations are visualized in Fig. 3 using the parameter values from Covington et al. (2012), which are deemed to represent reasonable estimates for limestone. It is evident that the thermal time scale is generally lower than the dissolution time scale. This means that variations in the electrical conductivity of the spring water may still be observable while the temperature response is strongly damped due the thermal interaction with the rock. It is further noteworthy that the thermal time scale is dependent on the duration of the recharge pulse (cf. Eq. 1) and that the maximum of the thermal time scale approached for large $(>1 \mathrm{~m})$ hydraulic diameters approximately equals the pulse duration.

Within the scope of this paper, the process time scales given by Eqs. (1) and (2) can be viewed as thresholds of the

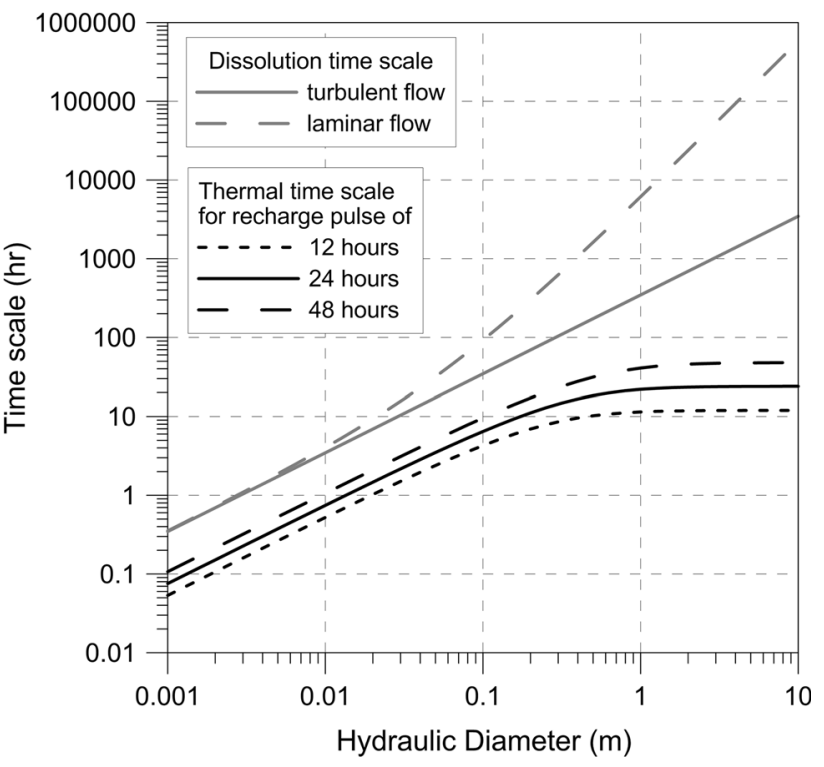

Fig. 3 Thermal time scale (Eq. 1) and dissolution time scales (Eq. 2) for thermal diffusivity of rock $\alpha_{\mathrm{r}}=1.14 \times 10^{-6} \mathrm{~m}^{2} \mathrm{~s}^{-1}$, ratio of the volumetric heat capacities of water and rock $\Psi=2.23$, and surfacereaction controlled dissolution rate constant under turbulent flow conditions $\alpha=2 \times 10^{-7} \mathrm{~m} \mathrm{~s}^{-1}$; the dissolution time scale for laminar flow conditions is calculated using a diffusion coefficient of $10^{-9} \mathrm{~m}^{2} \mathrm{~s}^{-1}$ for the correction of the rate constant according to Dreybrodt (1988). Note that the thermal time scale is dependent on the duration of the recharge pulse, whereas the dissolution time scale is not

travel time that can be used for the aquifer characterization as proposed by Fig. 1b. If physicochemical parameters of the water discharging at a spring respond to recharge events the travel time is suggested to be below the threshold; if variations in physicochemical parameters are absent or strongly damped the threshold is exceeded. As the threshold is dependent on the hydraulic diameter of the conduits (cf. Fig. 3), in principle it should be possible to infer minimum or maximum conduit diameters if the travel time can be estimated from tracer tests or lag times of the observed spring responses.

In the following capabilities and limitations of this approach are illustrated using the example of the Hammerbach spring. Figure 4 shows the electrical conductivity and the temperature of the water discharging at this spring from September 1997 to September 2009. Both parameters show a seasonal variation, which makes it difficult to identify the short-term responses to recharge events. To remove the seasonal variation a moving average with a 7-day window was subtracted from the data. The resulting curves reveal that both electrical conductivity and water temperature are generally responsive to recharge events as indicated by an obvious correlation with the peaks in the spring hydrograph. However, the water temperature 
exhibits only very weak variability within the time period from 2006 to 2009. Applying the above outlined concept to this observation suggests that within this time period the travel time generally exceeded the threshold for the damping of thermal responses. In contrast, changes in the behavior of the electrical conductivity are not apparent suggesting that the travel time remained below the threshold given by the dissolution time scale.

As the travel time is likely to be inversely related to discharge (i.e. decreasing travel time with increasing discharge) it is an obvious idea to assume that the travel time exceeded the thermal threshold because the spring discharge was less flashy and stayed well below $400 \mathrm{l} / \mathrm{s}$ in the time period from 2006 to 2009, whereas this value was surpassed several times in the years before. A closer look, however, reveals that in the years before 2006 short-term variations of the water temperature were observed even if the peak discharge was only between approximately 200 and $300 \mathrm{l} / \mathrm{s}$, whereas similar events within the period from 2006 to 2009 caused none or little temperature variation. Thus, if the thermal threshold defined by Eq. (1) is assumed to be constant, the travel times within this time period must have been higher than those at similar hydrological conditions in the years before. Yet, the finding that the travel times generally exceeded the thermal threshold from 2006 to 2009 can also be explained by a decreased thermal threshold within this time period relative to the years before. This would further imply a change in one or several parameters of Eq. (1), most likely a reduction of the hydraulic diameter.

In summary, the concept of transport thresholds developed and applied in this section proves useful for the identification of a change in the behavior of physicochemical parameters of the Hammerbach spring and provides some insight into the potential causes for this change. However, a unique identification of the mechanism causing the observed change does not appear to be possible based on the physicochemical data alone. Thus, the following discussion combines the above findings with results from tracer tests and hydrograph analysis.

\section{Discussion}

In the previous section, it was proposed that increased travel times in the time period from 2006 to 2009 relative to those in the years before are a potential cause of the observed change in the variability of the water temperature at the Hammerbach spring. One approach to obtain information about travel times is tracer testing. As mentioned in "Field site" section, results from tracer tests are reported by Behrens et al. (1992) and can be used for assessing travel times before 2006, which can be compared with the aforementioned tracer test conducted in 2008 (Oswald
2009; Wagner et al. 2011b). In 2008, the peak arrival time was found to be approximately $60 \mathrm{~h}$ after the tracer injection and the Hammerbach discharge varied approximately from 90 to $140 \mathrm{l} / \mathrm{s}$. In comparison, Behrens et al. (1992) report lower peak arrival times ranging from 38 to $47 \mathrm{~h}$ for tracer tests conducted in 1966, 1971, and 1979 when the Hammerbach discharge ranged overall between 120 and 146 l/s (but varied less during each of the individual tests). However, a higher peak arrival time of $69 \mathrm{~h}$ was found in 1983 when the discharge ranged between 113 and 119 l/s. The interpretation of the different peak arrival times thus is complicated by the fact that the spring discharge during the test in 2008 was more variable than that during the earlier tests. In addition, relevant hydrological conditions such as the relative contribution of allogenic and autogenic recharge components can be different even if the spring discharge is similar. The variability of travel times apparent from the three aforementioned tests conducted at a similar discharge is potentially explained by such hydrological differences. Despite the inherent limitation in the interpretation of the tracer test results it can be concluded that a change in travel times under similar hydrological conditions at least is not evident from the existing data. Thus, in the following the alternative hypothesis is considered that a change occurred in the thermal time scale given by Eq. (1), which defines a threshold for the travel time that must be exceeded to cause a strong damping of the thermal response at the spring.

Given that the thermal properties of water and rock can be assumed to be constant in time, this hypothesis implies a change in the hydraulic diameters of the conduits. More precisely, the strongly damped thermal response apparent in the time period from 2006 to 2009 suggests a conduit diameter lower than that before 2006. This assumption is generally consistent with the aforementioned change in the behavior of the spring hydrograph, which is less flashy in the time period from 2006 to 2009 than before. This is demonstrated by Mayaud et al. (2013) using cells of reduced hydraulic conductivity in a groundwater model to represent the effect of reduced conduit diameters in the Lurbach karst aquifer. These authors also show that the changed discharge behavior apparent from 2006 to 2009 manifests itself in changes of the flow duration curve and recession characteristics. The latter suggests that the changes in the spring hydrograph are caused by changes in aquifer properties rather than by changes in the hydrometeorological forcing. It should be noted, however, that the hydrograph recession can be influenced over periods of days or even weeks by the characteristics of the preceding recharge event and thus at least partly by the hydro-meteorological conditions (Birk and Hergarten 2010).

To examine further whether the changed discharge behavior from 2006 to 2009 is caused by changes in aquifer 
properties or hydro-meteorological conditions Wagner et al. (2013a) applied a rainfall-runoff model. The time period from 1997 to 2009 was subdivided in three periods, which were alternatingly used for calibration and validation. Whereas the model proved successful when the two time periods before 2006 were used for calibration and validation, the models that were calibrated using a time period before 2006 failed to reproduce the hydrograph observed from 2006 to 2009 and vice versa. As the rainfallrunoff model accounts for the observed hydro-meteorological conditions, this provides some indication that the changed discharge behavior is due to changes in aquifer properties. In fact, the parameter estimates obtained from the model calibration suggest an increased storage capacity from 2006 to 2009.

Conceptually, the finding from the rainfall-runoff modeling is consistent with the hypothesis of a decreased conduit diameter, because the water level and thus the storage in the karst system will be higher for a given discharge if the diameter and thus the hydraulic conductivity of the conduit pathways is reduced. This is also consistent with the observation of an overflow from the Hammerbach system to the Schmelzbach spring in 2008 (see "Field site" section), which was not observed during the above-mentioned earlier tracer tests under similar discharge conditions. The results from tracer tests reported by Behrens et al. (1992) suggest that the overflow occurred only if the discharge exceeded a threshold of approximately $200 \mathrm{l} / \mathrm{s}$. Reduced conduit diameters in the years from 2006 to 2009 imply that the threshold water level needed for the activation of conduit pathways toward the Schmelzbach is reached at a lower discharge. The tracer recovery at the Schmelzbach outlet in 2008, which occurred at a Hammerbach spring discharge of only $140 \mathrm{l} / \mathrm{s}$, supports this conceptual model.

Assuming the relationship between Hammerbach spring discharge and tracer peak arrival times from Behrens et al. (1992) was still valid the maximum discharge values (around $300 \mathrm{l} / \mathrm{s}$ ) encountered between 2006 and 2009 correspond to travel times of about one day. This is sufficiently low to allow the propagation of thermal pulses from recharge events that exceed one day provided the conduit diameter exceeds several decimeters (Fig. 3). The finding that the thermal variations are strongly damped over a period of 3 years thus suggests a conduit diameter well below a threshold of about $0.5 \mathrm{~m}$. As Fig. 4 does not reveal
Fig. 4 Discharge Q, water temperature $\mathrm{T}$ and electrical conductivity EC of the Hammerbach spring (from eHyd: http://ehyd.gv.at/; accessed on Dec. 28, 2012). To remove the seasonal variation of the physicochemical parameters, the moving average with a 7-day window was subtracted from the data, yielding filtered time series of water temperature $\mathrm{T}_{\text {filt }}$ and electrical conductivity $\mathrm{EC}_{\text {filt }}$

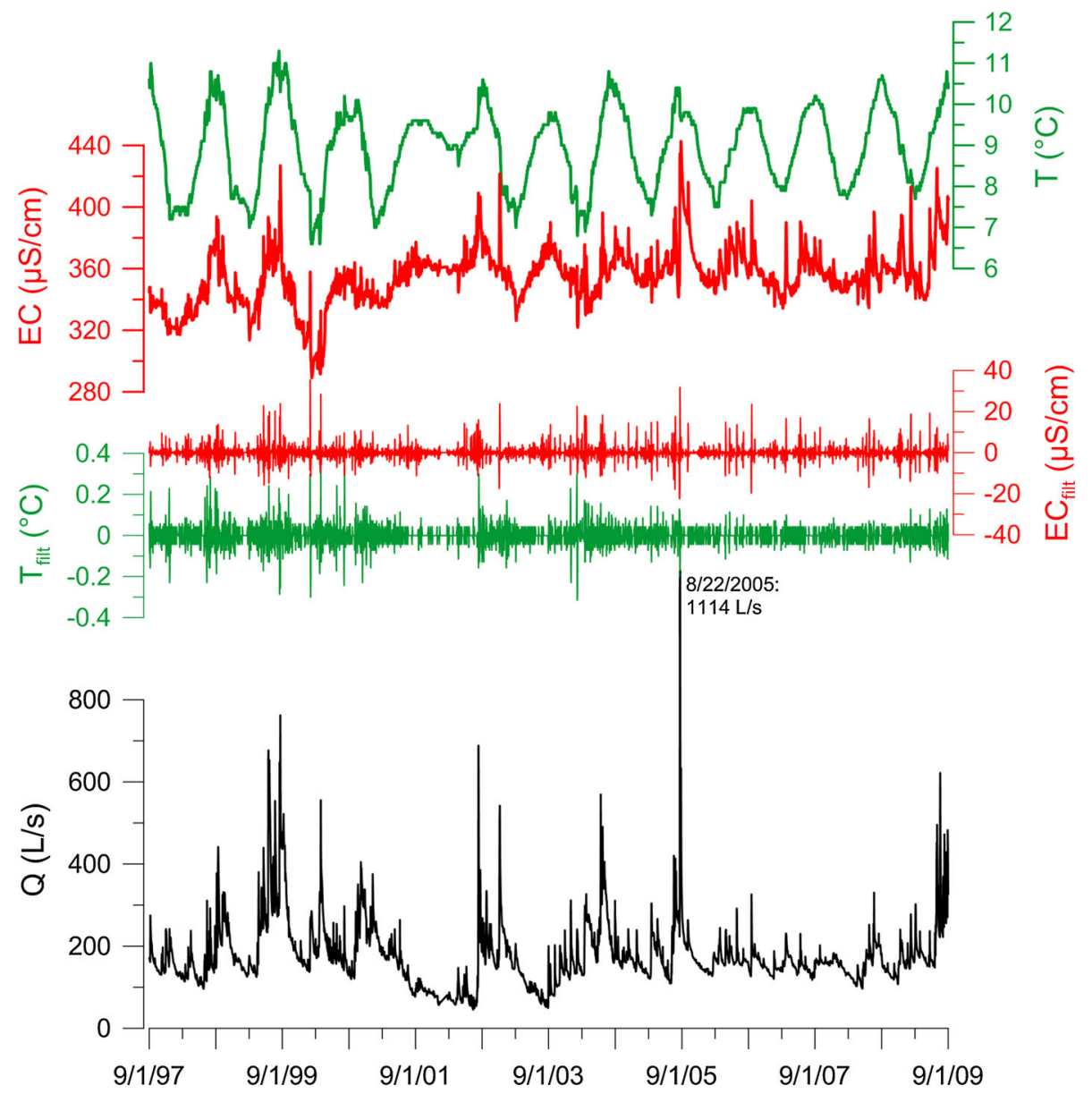


changes in the variability of the electrical conductivity, the dissolution time scale appears to be still larger than the travel time, which requires a minimum diameter of nearly $0.1 \mathrm{~m}$ (Fig. 3). The latter result, however, is based on the assumption that the electrical conductivity is controlled by the dissolution of limestone. This might be inappropriate here, as the allogenic recharge provided by the Lurbach stream delivers various compounds from agricultural and urban origin (Wagner et al. 2013b), some of which might contribute to the electrical conductivity of the water (e.g. road salt).

It should be noted that Covington et al. (2011) observed at one test site that the hydraulic diameter inferred from inverse heat transport modeling was lower than the actual diameter found in the cave system. This finding was attributed to the diffuse input of water that is thermally equilibrated with the rock. Similarly, flow in the Lurbach system represents a mixture of allogenic and autogenic flow components, and the observed change in the overflow from the Hammerbach to the Schmelzbach catchment possibly involves changes in the relative contribution of the two components to the Hammerbach spring discharge. As it is not entirely clear how this might affect the physicochemical response of the Hammerbach spring, the above estimated conduit diameters should be interpreted with caution. The inaccessibility of the Hammerbach drainage system precludes a determination of conduit diameters in the field. Nevertheless, the results from generic simulations of flow in coupled conduit-matrix (Birk 2002; Reimann et al. 2011) or reservoir-constriction (Covington et al. 2009) systems suggest that conduit diameters within the estimated range are probably low enough to cause strongly damped hydrograph responses, just as observed for the time period from 2006 to 2009.

From the above discussion the question arises what mechanism may have caused a change in the conduit diameters within the Lurbach karst system? It is known that karst systems accumulate sediments that can be mobilized and redistributed during storm events if a threshold velocity is crossed (Herman et al. 2008). Within the Lurbach system such processes are evident in the accessible cave, which is part of the Schmelzbach catchment (Wagner et al. 2013a). After intense recharge events, large quantities of sediments are redistributed by the flood water thereby blocking passages or destroying foot paths. As a result, passages that were once easily passed now need to be traversed by crawling on all fours or be cleared manually. Most likely, sediment redistributions also occur within the inaccessible conduit system of the Hammerbach spring, which provides a potential explanation for the supposed change in conduit diameters. This hypothesis is supported by the fact that the changed behavior of the spring hydrograph and the water temperature is preceded by the major flood event within the observation period. In addition, an apparent return to a more flashy discharge behavior suggested by the most recent data from 2009 fits well to the proposed mechanism, as it is plausible that constricted conduit passages are widened when accumulated sediments are re-mobilized by subsequent recharge events.

\section{Conclusion}

The example of the Lurbach system illustrates various types of thresholds in karst aquifers. Different controls on thresholds in the response of the system can be identified from tracer tests and physicochemical data. The tracer test data reveals an overflow from the Hammerbach system to the Schmelzbach catchment if a threshold discharge of the Hammerbach spring is exceeded; the underlying control most likely is the water level within the karst system, which needs to be sufficiently high to cause the flooding of conduit pathways at a distinct elevation. Responses of the physicochemical parameters of the spring water are strongly damped if the travel time exceeds a threshold value, which is dependent on the hydraulic diameter of the conduits.

The tracer test data and the physicochemical data reveal that within the time period from 2006 to 2009 both of these thresholds were different than in the years before: The overflow from the Hammerbach system to the Schmelzbach catchment was found to occur at lower discharge, and the response of the water temperature at the Hammerbach spring was more strongly damped. At the same time, the analysis of the spring hydrograph reveals changes in the discharge behavior too. A consistent explanation of these observations is provided by a reduction of conduit diameters within the karst system presumably due to the redistribution of sediments associated with a flood event in 2005. Hence, the analysis of response thresholds in the Lurbach system reveals that a functional threshold was crossed such that the flow and transport behavior within this system was changed over a period of several years. The occurrence of such changes in the functioning of karst systems obviously poses great challenges to the prediction of flow and transport phenomena in this type of setting. Yet, the example of the Lurbach system demonstrates that an adequate understanding of process and response thresholds can be derived and employed for the characterization of the properties and dynamics of karst hydrological systems.

Acknowledgments This work was funded by the Austrian Academy of Sciences (project "Global models of spring catchment") and by the Austrian Science Fund (FWF): L 576-N21. The Hammerbach spring data were provided by eHyd (http://ehyd.gv.at/). We thank Ralf Benischke for fruitful discussions about the Lurbach karst system. 
This work also benefited from discussions within the faculty of the doctoral programme (DK) "Climate Change Uncertainties, Thresholds and Coping Strategies" funded by the Austrian Science Fund (FWF): W1256.

Open Access This article is distributed under the terms of the Creative Commons Attribution License which permits any use, distribution, and reproduction in any medium, provided the original author(s) and the source are credited.

\section{References}

Behrens H, Benischke R, Bricelj M, Harum T, Käss W, Kosi G, Leditzky HP, Leibundgut C, Maloszewski P, Maurin V, Rajner V, Rank D, Reichert B, Stadler H, Stichler W, Trimborn P, Zojer H, Zupan M (1992) Investigations with natural and artificial tracers in the karst aquifer of the Lurbach system (PeggauTanneben-Semriach, Austria). Steir Beitr Hydrogeol 43:9-158

Birk S (2002) Characterisation of karst systems by simulating aquifer genesis and spring responses: Model development and application to gypsum karst. Tübinger Geowissenschaftliche Arbeiten C60. Dissertation, University of Tübingen

Birk S, Hergarten S (2010) Early recession behaviour of spring hydrographs. J Hydrol 387:24-32. doi:10.1016/j.jhydrol.2010. 03.026

Birk S, Liedl R, Sauter M (2006) Karst spring responses examined by process-based modeling. Ground Water 44(6):832-836. doi:10. 1111/j.1745-6584.2006.00175.x

Bonacci O, Željković I, Galić A (2013) Karst rivers' particularity: an example from Dinaric karst (Croatia/Bosnia and Herzegovina). Environ Earth Sci 70(2):963-974. doi:10.1007/s12665-0122187-9

Brown C, Wilby RL (2012) An alternate approach to assessing climate risks. EOS 93(41):401-412. doi:10.1029/2012EO410001

Covington MD, Wicks CM, Saar MO (2009) A dimensionless number describing the effects of recharge and geometry on discharge from simple karstic aquifers. Water Resour Res 45:W11410. doi:10.1029/2009WR008004

Covington M, Luhmann AJ, Gabrovšek F, Saar MO, Wicks CM (2011) Mechanisms of heat exchange between water and rock in karst conduits. Water Resour Res 47:W10514. doi:10.1029/ 2011WR010683

Covington MD, Luhmann AJ, Wicks CM, Saar MO (2012) Process length scales and longitudinal damping in karst conduits. J Geophys Res 117:F01025. doi:10.1029/2011JF002212

Dreybrodt W (1988) Processes in karst Systems (series in physical environment). Springer, Berlin, pp 140-182
Herman EK, Toran L, White WB (2008) Threshold events in spring discharge: evidence from sediment and continuous water level measurement. J Hydrol 351:98-106

Mayaud C, Wagner T, Benischke R, Birk S (2013) Understanding changes in the hydrological behaviour within a karst aquifer (Lurbach system, Austria). Carbonate Evaporite. doi:10.1007/ s13146-013-0172-3

Oswald S (2009) Künstliche und natürliche Tracer in einem Karsteinzugsgebiet mit allochthoner Neubildung (Lurbach, Österreich). Unpublished Bachelor thesis, University of Graz

Ravbar N, Barberá JA, Petrič M, Kogovšek J, Andreo B (2012) The study of hydrodynamic behaviour of a complex karst system under low-flow conditions using natural and artificial tracers (the catchment of the Unica River, SW Slovenia). Environ Earth Sci 65(8):2259-2272. doi:10.1007/s12665-012-1523-4

Reimann T, Rehrl C, Shoemaker WB, Geyer T, Birk S (2011) The significance of turbulent flow representation in single-continuum models. Water Resour Res 47:W09503. doi:10.1029/2010WR 010133

Terzić J, Marković T, Lukač Reberski J (2014) Hydrogeological properties of a complex Dinaric karst catchment: Miljacka Spring case study. Environ Earth Sci. doi:10.1007/s12665-0133031-6

Wagner T, Fabel D, Fiebig M, Häuselmann P, Sahy D, Xu S, Stüwe K (2010) Young uplift in the non-glaciated parts of the Eastern Alps. Earth Planet Sci Lett 295:159-169

Wagner T, Fritz H, Stüwe K, Nestroy O, Rodnight H, Hellstrom J, Benischke R (2011a) Correlations of cave levels, stream terraces and planation surfaces along the River Mur-timing of landscape evolution along the eastern margin of the Alps. Geomorphology 134:62-78. doi:10.1016/j.geomorph.2011.04.024

Wagner T, Mayaud C, Oswald S, Rinder T, Leis A, Stadler H, Benischke R, Birk S (2011b) Understanding intercatchment flow in a karst aquifer-using the Lurbach system example (Eastern Alps-Austria). Geophys Res Abstr 13, EGU2011-7962

Wagner T, Mayaud C, Benischke R, Birk S (2013a) Ein besseres Verständnis des Lurbach-Karstsystems durch ein konzeptionelles Niederschlags-Abfluss-Modell. Grundwasser 18(4):225-235. doi:10.1007/s00767-013-0234-4

Wagner T, Bollmann UE, Bester K, Birk S (2013b) Pesticides and biocides in a karst catchment: Identification of contaminant sources and related flow components. Geophys Res Abstr 15, EGU2013-11267

Zehe E, Sivapalan M (2009) Threshold behaviour in hydrological systems as (human) geo-ecosystems: manifestations, controls, implications. Hydrol Earth Syst Sci 13:1273-1297 